\title{
O MIX DE MARKETING DE SERVIÇOS E A LEALDADE DE UM CONSUMIDOR DE SERVIÇOS HOTELEIROS
}

Karine Brandão ${ }^{1}$

Ana Flávia Carlos ${ }^{2}$

Renata França ${ }^{2}$

Marcelo Silva Ângelo Ferreira ${ }^{2}$

\footnotetext{
${ }^{1}$ FUNCESI / Fundação Comunitária de Ensino Superior de Itabira

${ }^{2}$ Fundação Comunitária de Ensino Superior de Itabira
} 


\section{O MIX DE MARKETING DE SERVIÇOS E A LEALDADE DE UM CONSUMIDOR DE SERVIÇOS HOTELEIROS}

Resumo: Este presente artigo teve como objetivo identificar se os elementos mix de marketing de serviços utilizados pelas empresas do setor hoteleiro levam a retenção do cliente e em uma possível lealdade. Desta forma, foi realizada uma pesquisa de campo do tipo descritiva, com abordagem quantitativa, obteve-se 1001 respondentes, de forma não-probabilística por acessibilidade. Identificou-se que os elementos do mix de marketing de serviços influenciam na retenção e na lealdade dos respondentes perante os serviços de hospedagem. Destacou-se a necessidade emocional como o principal fator de escolha de uma hospedagem. Dos elementos do mix de marketing de serviços destacam-se a praça, preço e processos. A retenção dos respondentes oriunda dos elementos do mix de marketing de serviços se destacou no quesito pessoas. Os respondentes concordaram em maior parte que podem ser leais a uma empresa do setor hoteleiro quando são utilizados os elementos do mix de marketing de serviços.

Palavras-chave: Necessidade de compra. Serviços. Mix de marketing. Retenção. Lealdade.

\section{Introdução}

Diante do cenário econômico atual, observa-se um elevado nível competitivo, cada vez mais os clientes possuem uma diversidade de prestadoras de serviços para considerarem em seu processo decisório. Por esse motivo as empresas buscam atender as necessidades dos clientes a fim de satisfazê-los em curto, médio e longo prazo, proporcionando diferencial competitivo.

Com a modernização, a diversificação de novas formas de hospedagem passa a se tornar uma realidade. Assim os hotéis devem-se adaptar, buscando no mix de marketing alternativas de otimização necessárias para atender as necessidades do público em potencial.

Neste contexto, este estudo apresenta o seguinte problema: Os elementos do mix de marketing adotadas pelos hotéis podem impactar em uma retenção e em uma futura lealdade?

Assim, o objetivo deste artigo é identificar se os elementos do mix de marketing de serviços adotados pelas empresas hoteleiras podem impactam na retenção dos clientes e em uma futura lealdade. Os objetivos intermediários dividem-se em: (a) Identificar o perfil dos respondentes; (b) Identificar a necessidade da compra; (c) Identificar a percepção do consumidor em relação ao Mix de Marketing de Serviços; (d) Identificar se o Mix de Marketing de Serviços influencia na retenção de cliente; (e) Identificar se a retenção leva a lealdade.

Desta forma, o trabalho foi estruturado em seções, apresentando o referencial teórico, a metodologia utilizada, a análise dos resultados e, por fim, as considerações finais. 


\section{Referencial teórico}

\subsection{Serviços em hotelaria}

Para Kotler (2010), serviço pode ser definido como o desempenho que uma parte oferece a outra, sendo essencialmente intangível e não resulta em propriedade de nada. Zeithalm, Bitner e Gremler (2014), definem serviço como atividade econômica cujo produto final não é uma construção ou um produto físico, geralmente consumido no momento em que é produzido e proporciona valor agregado em formas que são intangíveis a seu comprador direto.

Segundo Castelli (2000), uma empresa hoteleira pode ser entendida como uma organização que, mediante o pagamento de diárias, fornece alojamento aos clientes indiscriminadamente. Para Guimarães (2013) o conceito de hotelaria está em constante transformação, é a atividade que representa o processo de antecipar e satisfazer as necessidades do cliente.

Popp et al. (2007) descreve que hotelaria faz parte do setor de prestação de serviços e, assim, se caracteriza como um produto intangível (que não se pode tocar ou provar). Desta forma, a confiança no serviço é a maior garantia do consumidor.

De acordo com Martins (2019), o impacto do turismo gerou uma participação de US\$ 8,8 trilhões ao PIB mundial $(10,4 \%)$, uma alta de $3,9 \%$, superior à expansão da economia global (3,2\%), sendo responsável por 319 milhões de empregos sendo responsável pela abertura de 1 em cada 10 postos de trabalho. De acordo com o autor, o crescimento do mercado de viagens ficou à frente de diversos ramos importantes, tais como o de cuidados com a saúde $(3,1 \%)$ e tecnologias da informação $(1,7 \%)$, perdendo apenas para o de manufaturas $(4 \%)$.

Rossetto (2014) descreve que a excelência de serviços é o que caracteriza a hotelaria, tendo o acolhimento e a hospitalidade como base, oferecendo para o consumidor acomodações que os satisfaçam. Holanda e Nascimento (2012) afirmam que o objetivo dos hoteleiros tem sido tornar a hospedagem cada vez mais uma experiência memorável.

\subsection{Necessidade de compra}

Blackwell, Miniard e Engel (2009), Sheth, Mittal e Newman (2001) e Kotler e Keller (2012), descrevem o comportamento do cliente em relação a compra como ações físicas e intelectuais por consumidores de bens de consumo individual ou em grupo, em decorrência de decisões e ações de compra, para atenderem suas necessidades e desejos.

A decisão do consumidor de comprar um produto turístico é resultado de um processo complexo, de diversos fatores relacionados ao próprio consumidor e às influências externas que atuam sobre eles (SWARBROOKE; HORNER, 2002). Sheth, Mittal e Newman (2001) descrevem que o comportamento do indivíduo é motivado por cinco necessidades básicas: funcional; social; emocional; epistêmica e situacional, conforme apresentado no Quadro 1. 


\section{Quadro 1 - Comportamento do indivíduo}

\begin{tabular}{|l|l|}
\hline Necessidade & Característica \\
\hline Funcional & $\begin{array}{l}\text { Satisfação de uma intenção fisica ou funcional na compra de um produto ou serviço, ou seja, } \\
\text { que desperte a procura por ofertas que solucionem problemas referente ao consumo. }\end{array}$ \\
\hline Eocial & $\begin{array}{l}\text { Está relacionada a outras pessoas, segmentos demográficos, socioeconômicos ou culturais de } \\
\text { uma sociedade. A necessidade de status estimula a expectativa de que outros tenham em alta } \\
\text { estima. A necessidade de modelos, desejo de ter outros individuos que demonstre proceder. A } \\
\text { não-social, cuja necessidade não é realizada com base em outros indivíduos, somente da pró- } \\
\text { pria pessoa como necessidade de controle. }\end{array}$ \\
\hline Emocional & $\begin{array}{l}\text { Quando o indivíduo adquiri um produto ou serviço que proporciona sentimentos e emoções. As } \\
\text { emoções podem ser positivas e negativas ou emoções especificas, como esperança, medo, } \\
\text { arrependimento, culpa, vergonha e humores. As emoções como amor, por vezes representam } \\
\text { os sentimentos com relação a certas marcas ou posses. }\end{array}$ \\
\hline Epistêmica & $\begin{array}{l}\text { Está correlacionada às necessidades humanas de conhecer explorar algo novo, desconhecido, } \\
\text { estimulação sensorial, estimulação cognitiva, novidades, e as necessidades de reforço. }\end{array}$ \\
\hline Situacional & $\begin{array}{l}\text { Está relacionada à circunstância momentânea do indivíduo, tais como o tempo, não terá a dis- } \\
\text { ponibilidade do processo de escolha que pode levar em consideração outros fatores como, } \\
\text { preço, localização entre outros. }\end{array}$ \\
\hline
\end{tabular}

Fonte: Adaptado de Sheth, Mittal e Newman (2001) e Hoyer e Macinnis (2011)

Em concordância com os autores citados anteriormente, Blackwell, Miniard e Engel (2009, p. 103) afirmam que "o reconhecimento dessas necessidades leva os consumidores a um processo de tomada de decisão que determinam o que compram e o que consomem."

\subsection{Mix de marketing de serviços - 7 P's}

Para Kotler (2000), Churchill e Peter (2008) e Kotler e Armstrong (2009), o mix de marketing tradicional é o agrupamento de ferramentas denominadas 4 P's (preço, praça, promoção e produto), que as empresas utilizam para atingir seus objetivos no mercado. No entanto, para a abordagem de serviços, o mix de marketing sofreu uma adaptação, incluindo três novos P's: pessoas, processos e evidência física (KOTLER, 2000; LOVELOCK; WIRTZ; HEMZO, 2011).

\section{Quadro 2 - Mix de marketing de serviços}

\begin{tabular}{|l|l|l|}
\hline Mix & Definição & Autores \\
\hline Preço & É o valor monetário cobrado por um produto ou serviço. & Kotler e Armstrong (2014) \\
\hline Praça & Canais de distribuições pelo qual é ofertado um produto. & Churchill e Peter (2008) \\
\hline Promoção & $\begin{array}{l}\text { Meio que as organizações utilizam para promover seus produtos, } \\
\text { comunicar e informar sobre os seus beneficios. }\end{array}$ & Maso (2010) \\
\hline Produto & $\begin{array}{l}\text { Algo que pode ser oferecido para aquisição, uso ou consumo, } \\
\text { podendo este satisfazer os desejos e necessidades das pessoas. }\end{array}$ & Kotler e Armstrong (2014) \\
\hline Pessoas & Interação entre compradores e profissionais de uma empresa. & $\begin{array}{l}\text { Lovelock, Wirtz e Hemzo } \\
(2011)\end{array}$ \\
\hline Processos & Forma de criação entrega dos serviços aos clientes. & $\begin{array}{l}\text { Zeithalm, Bitner e Gremler } \\
(2014)\end{array}$ \\
\hline $\begin{array}{l}\text { Evidências } \\
\text { fisicas }\end{array}$ & $\begin{array}{l}\text { Aspectos referentes ao ambiente onde o serviço é produzido, } \\
\text { como instalações, equipamentos. }\end{array}$ & $\begin{array}{l}\text { Lovelock, Wirtz e Hemzo } \\
(2011)\end{array}$ \\
\hline
\end{tabular}

Fonte: Adaptado pelos autores (2019) 
Neste estudo, o produto se refere a estadias vendida pelos hotéis; as pessoas são representadas pelos funcionários dos hotéis; as evidências físicas são os aspectos palpáveis da hospedagem; os processos, são as etapas vivenciadas pelos consumidores, que oferecem elementos para a avaliação do cliente no segmento hoteleiro.

\subsection{Retenção de clientes}

De acordo com Zeithaml, Bitner e Gremler (2011), se as empresas soubessem o quanto gastam com a perda de um cliente, elas conseguiriam fazer avaliações mais precisas, acerca dos investimentos destinados a retê-los. Maestri Filho e Almeida (2010) complementam que a maior dificuldade de retenção de clientes está no comportamento dos mesmos, pois suas necessidades mudam constantemente.

\subsection{Lealdade}

Para Grönroos (2009), lealdade não consiste exclusivamente que o cliente deve permanecer fiel à empresa, mas que a empresa também deve permanecer fiel ao cliente, a decorrência dessas atitudes mútuas se desenvolve com o tempo.

Lovelock (2006), entende que a lealdade ou a fidelidade é a disposição de um cliente para continuar a prestigiar uma empresa em longo prazo, comprar e utilizar seus serviços repetidamente, dar preferência e recomendar seus serviços e produtos aos seus colegas. De acordo com Kotler (2003), a expressão lealdade passou a ser usada como um conceito mais atual que fidelidade.

Lopes, Pereira e Vieira (2009) definem lealdade como o resultado de várias interações, nas quais o cliente adquire confiança nos serviços e produtos oferecidos pela organização. Oliver (1999), conceitua lealdade como um sentimento que garante a recompra de um produto ou serviço no futuro. Consiste no reflexo da percepção que o cliente possui sobre a probabilidade de repetidamente comprar em determinado estabelecimento ou contratar determinado serviço.

\section{Metodologia}

Para este trabalho foi utilizada a pesquisa quantitativa e descritiva. Assim, buscou-se descrever o perfil dos participantes e identificar se a adoção dos elementos do mix de marketing de serviços nas empresas hoteleiras pode levar a uma retenção de clientes e posteriormente à lealdade.

Desta forma, foi realizada uma pesquisa de campo. A pesquisa foi aplicada através de um formulário eletrônico disponibilizado na internet. A população foi formada por respondentes de diversos países, sendo a amostragem não probabilística por critérios de acessibilidade e conveniência. Para coleta de dados foi aplicado um questionário, que utilizou-se como base a Escala Likert, sendo (-1) "discordo totalmente", (-0,5) "discordo parcialmente", (0) "não concordo, nem discordo", $(0,5)$ "concordo parcialmente" e (1) "concordo totalmente". 
A presente pesquisa apresentou-se a técnica estatística descritiva, e obteve-se como principais limitações: (a) o instrumento de pesquisa ficou extenso, demandando tempo e atenção dada as pesquisadoras e dos respondentes, e; (b) resistência por parte de alguns respondentes sobre link disponibilizado para acessar o questionário, se não tratava de vírus.

\section{Análise de resultados}

O processo de coleta de dados foi realizado entre os dias 24 de abril a 15 de maio de 2019 , foram respondidos 1001 formulários.

\subsection{Perfil dos respondentes}

Respondendo o primeiro objetivo específico de "identificar o perfil dos respondentes", foi aplicado um questionário aos respondentes, sendo os dados obtidos alocados na Tabela 1.

Tabela 1 - Análise do Perfil dos Respondentes

\begin{tabular}{|c|c|c|}
\hline Perfil & Número de vezes apontado & \% sobre 1001 \\
\hline \multicolumn{3}{|l|}{ Gênero } \\
\hline Feminino & 602 & $60 \%$ \\
\hline Masculino & 399 & $40 \%$ \\
\hline Total & 1001 & $100 \%$ \\
\hline \multicolumn{3}{|l|}{ Idade } \\
\hline Menor que 18 anos & 9 & $1 \%$ \\
\hline Entre 18 a 30 anos & 324 & $32 \%$ \\
\hline Entre 31 a 40 anos & 300 & $30 \%$ \\
\hline Entre 41 a 50 anos & 237 & $24 \%$ \\
\hline Acima de 51 anos & 131 & $13 \%$ \\
\hline Total & 1001 & $100 \%$ \\
\hline \multicolumn{3}{|l|}{ Renda } \\
\hline Até R\$ 11.976,00 & 428 & $43 \%$ \\
\hline De $R \$ 11.976,01$ a $R \$ 23.952,00$ & 159 & $16 \%$ \\
\hline De $R \$ 23.952,01$ a $R \$ 47.904,00$ & 177 & $18 \%$ \\
\hline De $R \$ 47.904,01$ a $R \$ 59.880,00$ & 68 & $7 \%$ \\
\hline Acima de $\mathrm{R} \$ 59.880,01$ & 169 & $17 \%$ \\
\hline Total & 1001 & $100 \%$ \\
\hline \multicolumn{3}{|l|}{ Sua residência atual? } \\
\hline Brasil & 844 & $84 \%$ \\
\hline Outros Países & 157 & $16 \%$ \\
\hline Total & 1001 & $100 \%$ \\
\hline \multicolumn{3}{|c|}{ Me hospedo mais pelo seguinte motivo: } \\
\hline Estudo & 35 & $3 \%$ \\
\hline Lazer & 673 & $67 \%$ \\
\hline Trabalho & 204 & $20 \%$ \\
\hline Visitas à família & 39 & $4 \%$ \\
\hline Outros & 50 & $5 \%$ \\
\hline Total & 1001 & $100 \%$ \\
\hline
\end{tabular}

Fonte: elaborada pelos autores (2019) 
A Tabela 1 mostra que a maioria dos respondentes é do gênero feminino (60\%), a faixa etária entre 18 a 40 anos somaram-se 624 respondentes, representando (62\%). A maior parte deles (57\%) possui renda anual acima de doze salários mínimos e 844 respondentes residem no Brasil representando $84 \%$ da pesquisa.

\subsection{Necessidade de compra}

Com intuito de responder o segundo objetivo específico, de "Identificar a necessidade compra" foi feita análise dos dados obtidos e apresentados na Tabela 2.

\section{Tabela 2 - Necessidade de Compra}

\begin{tabular}{lcccccc} 
& $\begin{array}{c}\text { Discordo } \\
\text { totalmente }\end{array}$ & $\begin{array}{c}\text { Discordo } \\
\text { parcialmente }\end{array}$ & $\begin{array}{c}\text { Não concordo, } \\
\text { nem discordo }\end{array}$ & $\begin{array}{c}\text { Concordo } \\
\text { parcialmente }\end{array}$ & $\begin{array}{c}\text { Concordo } \\
\text { totalmente }\end{array}$ & $\begin{array}{c}\text { Ranking } \\
\text { Médio }\end{array}$ \\
\hline $\begin{array}{l}\text { 1- Escolho a minha hospedagem de } \\
\text { acordo com a minha motivação. }\end{array}$ & $8 \%$ & $13 \%$ & $15 \%$ & $39 \%$ & $25 \%$ & $\mathbf{0 , 3 0}$ \\
\hline $\begin{array}{l}\text { 2- Prefiro me hospedar em hotéis de } \\
\text { classe mais elevada (luxuosos). }\end{array}$ & $28 \%$ & $23 \%$ & $17 \%$ & $27 \%$ & $5 \%$ & $\mathbf{- 0 , 2 0}$ \\
\hline $\begin{array}{l}\text { 3- Prefiro me hospedar em hotéis } \\
\text { que elevam meu status social. }\end{array}$ & $61 \%$ & $14 \%$ & $13 \%$ & $10 \%$ & $3 \%$ & $\mathbf{- 0 , 6 0}$ \\
\hline $\begin{array}{l}\text { 4- Prefiro hotéis que me } \\
\text { proporcionam } \\
\text { agradáveis. }\end{array}$ & $2 \%$ & $3 \%$ & $4 \%$ & $28 \%$ & $63 \%$ & $\mathbf{0 , 7 4}$ \\
\hline $\begin{array}{l}\text { 5- Procuro novas experiências em } \\
\text { hospedagens. }\end{array}$ & $7 \%$ & $9 \%$ & $22 \%$ & $38 \%$ & $23 \%$ & $\mathbf{0 , 3 1}$ \\
\hline $\begin{array}{l}\text { 6- Dependendo do motivo da minha } \\
\text { viagem não comparo serviços de } \\
\text { hotelaria. }\end{array}$ & $31 \%$ & $20 \%$ & $13 \%$ & $26 \%$ & $10 \%$ & $\mathbf{- 0 , 1 8}$ \\
\hline Ranking Geral & & & & & & \\
\hline
\end{tabular}

De acordo os dados apresentados na Tabela 2, os respondentes tiveram a percepção positiva em relação às situações apresentadas, resultou-se em um ranking geral $(0,06)$ demonstrando neutralidade dos respondentes sobre as afirmativas expostas.

Na primeira afirmativa tratou-se da necessidade situacional, obteve-se um ranking médio $(0,30)$, a uma neutralidade por parte dos respondentes. Diante o resultado, demonstrou-se que os respondentes escolhem suas hospedagens de acordo com a sua motivação. Conforme Sheth, Mittal e Newman (2001), descrevem como necessidade situacional a circunstância momentânea que o indivíduo se encontra.

A segunda e terceira afirmativas, estão relacionadas as necessidades sociais, há uma preferência em se hospedar em hotéis de classes mais elevadas, 502 respondentes discordaram, sendo que $28 \%$ discordaram totalmente e $23 \%$ discordaram parcialmente. Sobre hospedar em hotéis que elevam o status social $61 \%$ discordaram totalmente e $14 \%$ discordaram parcialmente, no total de 746 respondentes ambas obtiveram ranking médio negativo $(-0,20)$ e $(-0,60)$. Hoyer e Macinnis (2011) descrevem que as necessidades sociais estão relacionadas a outras pessoas, correlacionadas com o status que pode estimular a expectativa de que outros tenham em alta 
estima. Neste contexto é perceptível que os respondentes não consideraram está necessidade relevante.

A quarta afirmativa, relacionada à necessidade emocional, resultou-se em um ranking médio $(0,74)$, dos quais $28 \%$ concordaram parcialmente e $63 \%$ concordaram totalmente, em um total de 910 respondentes que preferem hotéis que proporcionam momentos agradáveis, representando 91\% dos entrevistados. De acordo com Sheth, Mittal e Newman (2001), as necessidades emocionais estão correlacionadas aos sentimentos benevolentes.

A quinta afirmativa, sobre necessidades epistêmicas, com o ranking médio $(0,31)$, evidenciou neutralidade dos respondentes, tendencioso a concordância parcial. De modo geral 616 respondentes concordaram com o quesito, em que $38 \%$ concordaram parcialmente e $23 \%$ concordaram totalmente.

A sexta afirmativa, direcionada a necessidade situacional, resultou um ranking médio $(-0,18)$, houve uma tendência a discordância dos respondentes. Foram 514 respondentes que discordaram da afirmativa, sendo que $20 \%$ discordaram parcialmente e $31 \%$ discordaram totalmente.

No contexto geral das asserções relacionadas as necessidades de compra, obteve-se um ranking geral $(0,06)$, demonstrou-se uma neutralidade dos respondentes.

\subsection{Mix de marketing de serviços}

O terceiro objetivo do trabalho, de "Identificar se o mix de marketing influencia na retenção dos clientes nos hotéis", foi feita a análise de dados obtidos através dos questionários. A Tabela 3 , aponta os dados referentes à percepção dos respondentes em relação às estratégias do mix de marketing de serviços influenciam na retenção dos clientes.

Tabela 3 - Mix de Marketing - Produto

\begin{tabular}{rcccccc}
\hline & $\begin{array}{c}\text { Discordo } \\
\text { totalmente }\end{array}$ & $\begin{array}{c}\text { Discordo } \\
\text { parcialmente }\end{array}$ & $\begin{array}{c}\text { Não concordo } \\
\text { nem discordo }\end{array}$ & $\begin{array}{c}\text { Concordo } \\
\text { parcialmente }\end{array}$ & $\begin{array}{c}\text { Concordo } \\
\text { totalmente }\end{array}$ & $\begin{array}{c}\text { Ranking } \\
\text { Médio }\end{array}$ \\
\hline $\begin{array}{l}1-\mathrm{O} \text { serviço/produto oferecido } \\
\text { pelo hotel é relevante para minha } \\
\text { compra. }\end{array}$ & $6 \%$ & $6 \%$ & $8 \%$ & $40 \%$ & $40 \%$ & $\mathbf{0 , 5 2}$ \\
\hline \multicolumn{5}{c}{ Ranking Geral } \\
\hline
\end{tabular}

De acordo com a Tabela 3 que resultou em um ranking geral $(0,52)$, apresentou concordância parcial por parte dos respondentes. Sendo que 803 respondentes $(80 \%)$ concordam parcialmente ou totalmente com a afirmativa que relaciona o produto oferecido pelo hotel com a relevância para a compra. O perfil identificado dos respondentes, relevante nesta asserção, foi do sexo feminino com $62 \%$ e com a renda anual de até doze salários mínimos. 
Tabela 4 - Mix de Marketing - Preço

\begin{tabular}{lccccccc}
\hline & $\begin{array}{c}\text { Discordo } \\
\text { totalmente }\end{array}$ & $\begin{array}{c}\text { Discordo } \\
\text { parcialmente }\end{array}$ & $\begin{array}{c}\text { Não concordo } \\
\text { nem discordo }\end{array}$ & $\begin{array}{c}\text { Concordo } \\
\text { parcialmente }\end{array}$ & $\begin{array}{c}\text { Concordo } \\
\text { totalmente }\end{array}$ & $\begin{array}{c}\text { Ranking } \\
\text { Médio }\end{array}$ \\
\hline $\begin{array}{l}\text { 2- Eu pesquiso preço antes de } \\
\text { reservar o hotel. }\end{array}$ & $1 \%$ & $1 \%$ & $2 \%$ & $14 \%$ & $83 \%$ & $\mathbf{0 , 8 8}$ \\
\hline $\begin{array}{l}\text { 3- Preço é determinante para minha } \\
\text { compra. }\end{array}$ & $2 \%$ & $4 \%$ & $6 \%$ & $42 \%$ & $46 \%$ & $\mathbf{0 , 6 3}$ \\
\hline \multicolumn{7}{r}{ Ranking Geral } \\
\hline
\end{tabular}

Conforme a Tabela 4 que apresentou duas afirmativas sobre o preço, resultou-se no ranking geral de $(0,76)$, sendo assim, houve uma concordância total pelos respondentes, demonstrando que para a maioria o preço é importante.

Na primeira afirmativa, pesquisa do preço antes da compra, 966 respondentes concordaram positivamente, sendo que, $(14 \%)$ concordaram parcialmente e $(83 \%)$ concordaram totalmente. Apresentou-se um ranking médio de $(0,88)$, com tendência a concordância total dos respondentes.

A segunda asserção teve o propósito de identificar se o preço é determinante para a compra, resultou-se em um ranking médio $(0,63)$, foram 878 entrevistados que concordaram com a afirmativa, do qual $42 \%$ concordaram parcialmente e $46 \%$ concordaram totalmente.

Em concordância, Churchill e Peter (2008) descrevem que as estratégias do preço são essenciais nas decisões de compra do consumidor, ou seja, os hotéis devem se preocupar com os preços ofertados a seus clientes, a fim de atender suas expectativas e se possível superá-las.

Tabela 5 - Mix de Marketing - Praça

\begin{tabular}{|c|c|c|c|c|c|c|}
\hline & $\begin{array}{c}\text { Discordo } \\
\text { totalmente }\end{array}$ & $\begin{array}{c}\text { Discordo } \\
\text { parcialmente }\end{array}$ & $\begin{array}{l}\text { Não concordo } \\
\text { nem discordo }\end{array}$ & $\begin{array}{c}\text { Concordo } \\
\text { parcialmente }\end{array}$ & $\begin{array}{l}\text { Concordo } \\
\text { totalmente }\end{array}$ & $\begin{array}{c}\text { Ranking } \\
\text { Médio }\end{array}$ \\
\hline $\begin{array}{l}\text { 4- A localização do hotel } \\
\text { influencia na minha escolha de } \\
\text { acordo com a motivação da } \\
\text { viagem. }\end{array}$ & $1 \%$ & $2 \%$ & $2 \%$ & $30 \%$ & $65 \%$ & 0,78 \\
\hline Ranking Geral & & & 0,78 & & & \\
\hline
\end{tabular}

Fonte: elaborada pelos autores (2019)

Na Tabela 5 a afirmativa relacionada à localização do hotel, obteve um ranking geral de $(0,78)$ concordância total por grande maioria dos respondentes. É notória a influência desse quesito, teve-se um total de 954 respostas, sendo que, 30\% concordaram parcialmente e $65 \%$ concordaram totalmente.

Referente aos 7P's tratados, o elemento praça obteve-se a maior relevância no momento da escolha do hotel. Churchill e Peter (2008), descrevem que os canais de distribuições pelo qual é ofertado um produto ou serviço, influenciam na percepção dos clientes. 


\section{Tabela 6 - Mix de Marketing - Promoção}

5- Campanhas com promoções e planos de benefícios (milhas) me totalmente parcialmente nem discordo parcialmente

totalmente Médio
atraem.

$6 \%$

$6 \%$

$13 \%$

$31 \%$

$44 \%$

$\mathbf{0 , 5 1}$ descontos no meio digital influenciam na minha escolha do hotel.

Ranking Geral

$6 \%$

$6 \%$

$15 \%$

$42 \%$

$31 \%$

$\mathbf{0 , 4 2}$

Ranking Geral

Fonte: elaborada pelos autores (2019)

De acordo com a Tabela 6, as campanhas de promoções e planos de benefícios que podem ser ofertados, resultou-se em um ranking geral positivo de $(0,46)$ os respondentes demonstraram concordância parcial. A primeira asserção, apresentou um ranking médio $(0,51)$, perceptível a concordância parcial dos entrevistados. Resultou-se em 753 respondentes, dado que, 31\% concordaram parcialmente e $44 \%$ concordaram totalmente.

Em relação a segunda afirmativa, 726 respondentes consideraram ser influenciados pelas promoções e descontos no momento da escolha do hotel, apurou-se que $42 \%$ concordaram parcialmente e $31 \%$ concordaram totalmente. Atingiu-se um ranking médio de $(0,42)$, os respondentes concordaram parcialmente.

Os resultados obtidos estão em concordância com o autor Kotler (2000), que descrevem a promoção como são ações que incidem a respeito de certos produtos ou serviços, a fim de estimular a sua divulgação ou comercialização.

Tabela 7 - Mix de Marketing - Pessoas

\begin{tabular}{|c|c|c|c|c|c|c|}
\hline & $\begin{array}{c}\text { Discordo } \\
\text { totalmente }\end{array}$ & $\begin{array}{c}\text { Discordo } \\
\text { parcialmente }\end{array}$ & $\begin{array}{l}\text { Não concordo } \\
\text { nem discordo }\end{array}$ & $\begin{array}{c}\text { Concordo } \\
\text { parcialmente }\end{array}$ & $\begin{array}{l}\text { Concordo } \\
\text { totalmente } \\
\end{array}$ & $\begin{array}{l}\text { Ranking } \\
\text { Médio } \\
\end{array}$ \\
\hline $\begin{array}{l}\text { 7- Levo em consideração a } \\
\text { capacitação e atendimento dos } \\
\text { funcionários do hotel. }\end{array}$ & $3 \%$ & $5 \%$ & $13 \%$ & $32 \%$ & $46 \%$ & $\mathbf{0 , 5 7}$ \\
\hline Ranking Geral & & & $\mathbf{0 , 5 7}$ & & & \\
\hline
\end{tabular}

A Tabela 7 está relacionada a percepção dos respondentes sobre a capacitação e o atendimento dos funcionários, que resultou ranking geral de $(0,57)$ uma concordância parcial dos respondentes. Identificou-se que 788 respondentes concordaram com a assertiva, sendo que $32 \%$ concordaram parcialmente e $46 \%$ concordaram totalmente.

Neste contexto Lovelock, Wirtz e Hemzo (2011) apresentam pessoas como a interação entre clientes e funcionários de uma empresa, os autores explicam que a solução para alcançar as expectativas do cliente surge a partir do ajuste das capacidades pessoais dos funcionários. 
Tabela 8 - Mix de Marketing - Evidência Física

\begin{tabular}{|c|c|c|c|c|c|c|}
\hline & $\begin{array}{l}\text { Discordo } \\
\text { totalmente }\end{array}$ & $\begin{array}{c}\text { Discordo } \\
\text { parcialmente }\end{array}$ & $\begin{array}{l}\text { Não concordo } \\
\text { nem discordo }\end{array}$ & $\begin{array}{c}\text { Concordo } \\
\text { parcialmente }\end{array}$ & $\begin{array}{l}\text { Concordo } \\
\text { totalmente }\end{array}$ & $\begin{array}{c}\text { Ranking } \\
\text { Médio }\end{array}$ \\
\hline $\begin{array}{l}\text { 8- Prefiro hotéis que tenham } \\
\text { sofisticação no ambiente interno e } \\
\text { externo (ex.: arquitetura, moderna, } \\
\text { fácil estacionamento, qualidade } \\
\text { nos objetos dos quartos (colchão, } \\
\text { Tv, frigobar...). }\end{array}$ & $9 \%$ & $11 \%$ & $15 \%$ & $40 \%$ & $25 \%$ & $\mathbf{0 , 3 0}$ \\
\hline $\begin{array}{l}\text { 9- As acomodações do hotel são } \\
\text { relevantes para minha escolha. }\end{array}$ & $3 \%$ & $3 \%$ & $4 \%$ & $37 \%$ & $53 \%$ & 0,68 \\
\hline Ranking Geral & & & 0,43 & & & \\
\hline
\end{tabular}

A Tabela 8 apresenta afirmativas que estão associadas as evidências físicas, o grau de relevância que os respondentes têm sobre os ambientes físicos e instalações oferecidas pelos hotéis. Originou-se um ranking geral $(0,43)$ que apontou uma concordância parcial dos participantes da pesquisa.

A primeira afirmativa referente a sofisticação no ambiente interno e externo dos hotéis, obtevese 647 respondentes concordam parcialmente ou totalmente, dos quais $40 \%$ concordaram parcialmente e $25 \%$ concordaram totalmente. No quesito analisado apresentou um ranking médio $(0,30)$ que revela uma neutralidade por parte dos entrevistados.

A segunda asserção, descreve-se às acomodações oferecidas por um hotel, resultou um ranking médio $(0,68)$ havendo uma concordância total dos respondentes. Importante ressaltar que $37 \%$ dos participantes responderam que concordam parcialmente e $53 \%$ concordaram totalmente. $\mathrm{O}$ ranking médio resultou em $(0,68)$ que levou a uma concordância total. Zeithalm, Bitner e Gremler (2014), descrevem que nas evidências físicas contêm todos os aspectos palpáveis do serviço. Ou seja, pode ser vista como estratégia para hotéis que visa aumentar sua competitividade e sucesso.

Tabela 9 - Mix de Marketing - Processos

\begin{tabular}{|c|c|c|c|c|c|c|}
\hline & $\begin{array}{l}\text { Discordo } \\
\text { totalmente }\end{array}$ & $\begin{array}{c}\text { Discordo } \\
\text { parcialmente }\end{array}$ & $\begin{array}{l}\text { Não concordo } \\
\text { nem discordo }\end{array}$ & $\begin{array}{c}\text { Concordo } \\
\text { parcialmente }\end{array}$ & $\begin{array}{l}\text { Concordo } \\
\text { totalmente }\end{array}$ & $\begin{array}{c}\text { Ranking } \\
\text { Médio }\end{array}$ \\
\hline $\begin{array}{l}\text { 10- Levo em consideração os } \\
\text { processos organizacionais na hora da } \\
\text { minha escolha por um hotel (ex.: } \\
\text { café da manhã, segurança, limpeza e } \\
\text { organização do quarto). }\end{array}$ & $1 \%$ & $2 \%$ & $5 \%$ & $31 \%$ & $62 \%$ & 0,75 \\
\hline Ranking Geral & & & 0,75 & & & \\
\hline
\end{tabular}

Os processos internos e externos apresentados na Tabela 9, obteve-se um ranking geral $(0,75)$ que apontou uma tendência para a concordância total dos respondentes. Identificou-se que 925 respondentes concordaram, sendo que $31 \%$ deles concordaram parcialmente e $62 \%$ concordaram totalmente que levam em consideração os processos organizacionais. Zeithalm, 
Bitner e Gremler (2014), definem que processos são as etapas vivenciadas pelos consumidores, que oferecem elementos para a avaliação do cliente no segmento hoteleiro.

Os 7P's do mix de marketing de serviços foram analisados separadamente, a Tabela 10 apresenta o grau de importância que as estratégias são percebidas pelos respondentes.

Tabela 10 - Análise Geral dos 7P's

\begin{tabular}{cccccc}
\hline & $\begin{array}{c}\text { Discordo } \\
\text { totalmente }\end{array}$ & $\begin{array}{c}\text { Discordo } \\
\text { parcialmente }\end{array}$ & $\begin{array}{c}\text { Não concordo nem } \\
\text { discordo }\end{array}$ & $\begin{array}{c}\text { Concordo } \\
\text { parcialmente }\end{array}$ & $\begin{array}{c}\text { Concordo } \\
\text { totalmente }\end{array}$ \\
\hline Representatividade Geral \% & $6 \%$ & $6 \%$ & $9 \%$ & $33 \%$ & $46 \%$ \\
\hline Ranking geral & & & $\mathbf{0 , 5 3}$ & & \\
\hline & Fonte: elaborada pelos autores $(2019)$
\end{tabular}

Respondendo o terceiro objetivo específico, conclui-se que os elementos do mix de marketing de serviços foram bem avaliados pelos respondentes, obteve-se um ranking médio geral $(0,53)$, o que indica uma concordância parcial em relação aos elementos do mix de marketing de serviços.

\subsection{Retenção}

Buscando responder ao quarto objetivo de identificar se o mix de marketing de serviços influencia na retenção dos clientes. Conforme apresentados na Tabela 11.

Tabela 11 - Estratégias do Mix de Marketing - Retenção

\begin{tabular}{|c|c|c|c|c|c|c|}
\hline & $\begin{array}{l}\text { Discordo } \\
\text { totalmente }\end{array}$ & $\begin{array}{c}\text { Discordo } \\
\text { parcialmente }\end{array}$ & $\begin{array}{l}\text { Não concordo, } \\
\text { nem discordo }\end{array}$ & $\begin{array}{l}\text { Concordo } \\
\text { parcialmente }\end{array}$ & $\begin{array}{l}\text { Concordo } \\
\text { totalmente }\end{array}$ & $\begin{array}{l}\text { Ranking } \\
\text { Médio }\end{array}$ \\
\hline $\begin{array}{l}\text { 1- Serviços / Produtos ofertados pelo } \\
\text { hotel podem influenciar na minha } \\
\text { retenção enquanto cliente. }\end{array}$ & $2 \%$ & $3 \%$ & $15 \%$ & $44 \%$ & $36 \%$ & $\mathbf{0 , 5 3}$ \\
\hline $\begin{array}{l}\text { 2- Preço pode influenciar na minha } \\
\text { retenção enquanto cliente. }\end{array}$ & $1 \%$ & $2 \%$ & $5 \%$ & $41 \%$ & $52 \%$ & 0,71 \\
\hline $\begin{array}{l}\text { 3- A localização do hotel pode } \\
\text { influenciar na minha retenção } \\
\text { enquanto cliente. }\end{array}$ & $0 \%$ & $1 \%$ & $5 \%$ & $40 \%$ & $53 \%$ & 0,72 \\
\hline $\begin{array}{l}\text { 4- Promoções e descontos ofertados } \\
\text { pelo hotel podem influenciar na } \\
\text { minha retenção enquanto cliente. }\end{array}$ & $1 \%$ & $3 \%$ & $8 \%$ & $39 \%$ & $50 \%$ & 0,67 \\
\hline $\begin{array}{l}\text { 5- Um bom atendimento por parte } \\
\text { dos funcionários pode influenciar na } \\
\text { minha retenção enquanto cliente. }\end{array}$ & $1 \%$ & $1 \%$ & $4 \%$ & $27 \%$ & $67 \%$ & 0,79 \\
\hline $\begin{array}{l}\text { 6- A arquitetura interna e externa de } \\
\text { um hotel pode influenciar na minha } \\
\text { retenção enquanto cliente. }\end{array}$ & $8 \%$ & $10 \%$ & $22 \%$ & $42 \%$ & $18 \%$ & 0,27 \\
\hline 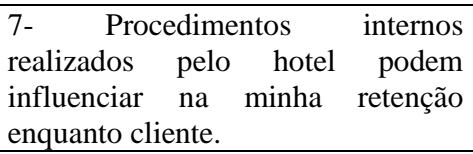 & $2 \%$ & $3 \%$ & $17 \%$ & $46 \%$ & $33 \%$ & $\mathbf{0 , 5 2}$ \\
\hline Ranking Geral & & & 0,60 & & & \\
\hline
\end{tabular}


Observou-se na Tabela 11 que as práticas do mix de marketing de serviços tendem a um grau de concordância pela maioria dos respondentes, representando $84 \%$ que concordam totalmente e parcialmente. Obteve-se um ranking geral de $(0,60)$, havendo uma concordância parcial pelos respondentes que tiveram a percepção positiva referente às estratégias do mix de marketing de serviços.

Em relação às afirmativas apresentadas na Tabela 11, é notória a tendência dos respondentes a um grau de concordância total, diante dos elementos: promoção $(0,67)$, preço $(0,71)$, praça $(0,72)$ e pessoas $(0,79)$. Obteve-se uma concordância parcial nos quesitos processos $(0,52) \mathrm{e}$ produto $(0,53)$. Sobre o quesito de evidências físicas resultou-se no ranking médio $(0,27)$ tendendo a neutralidade.

A afirmativa relacionada a pessoas, obteve-se 939 respondentes que concordaram positivamente, sendo que $27 \%$ concordaram parcialmente e $67 \%$ concordaram totalmente, resultou um ranking médio de $(0,79)$ que demonstrando a percepção do bom atendimento por meio dos funcionários por parte dos respondentes.

Em relação à praça, ranking médio de $(0,72)$, há uma tendência para concordância total, obtevese 933 respondentes que concordaram parcialmente e totalmente. O preço, obteve-se ranking médio de $(0,71)$, tendendo para uma concordância total, onde 930 respondentes concordaram parcialmente e totalmente.

Conforme descrito, o quarto objetivo foi respondido, visto que identificou que os elementos do mix de marketing de serviços, influenciam na retenção dos clientes, com ranking médio geral $(0,60)$, ou seja, tendência para a concordância parcial.

\subsection{Lealdade}

Respondendo ao quinto objetivo específico de "Identificar se a retenção leva a lealdade", os dados obtidos foram alocados na Tabela 12 .

Tabela 12 - Lealdade

\begin{tabular}{ccccccc}
\hline & $\begin{array}{c}\text { Discordo } \\
\text { totalmente }\end{array}$ & $\begin{array}{c}\text { Discordo } \\
\text { parcialmente }\end{array}$ & $\begin{array}{c}\text { Não concordo } \\
\text { nem discordo }\end{array}$ & $\begin{array}{c}\text { Concordo } \\
\text { parcialmente }\end{array}$ & $\begin{array}{c}\text { Concordo } \\
\text { totalmente }\end{array}$ & $\begin{array}{c}\text { Ranking } \\
\text { Médio }\end{array}$ \\
\hline $\begin{array}{l}\text { 1- Com a minha retenção enquanto } \\
\text { cliente, estou propenso a ser leal } \\
\text { em compras futuras. }\end{array}$ & $3 \%$ & $3 \%$ & $14 \%$ & $44 \%$ & $36 \%$ & $\mathbf{0 , 5 4}$ \\
\hline Ranking Geral & Fonte: elaborada pelos autores (2019) & & & & & \\
\hline & & & &
\end{tabular}

A Tabela 12 apresentou que $80 \%$ dos respondentes concordaram que ao serem retidos estão propensos a se tornarem leais. Se faz relevante detalhar que $44 \%$ concordaram parcialmente e $36 \%$ concordou totalmente, que equivale a 805 respondentes. Obteve-se um ranking geral $(0,54)$, resultado tendendo para a concordância parcial dos entrevistados. 
Destes, $61 \%$ pertencerem ao sexo feminino, $85 \%$ com faixa etária entre 18 a 50 anos, sendo que $85 \%$ residem no Brasil, $67 \%$ afirmaram que se hospedam mais por lazer, $58 \%$ possuem renda anual de 12 a 24 salários mínimos, $92 \%$ afirmou se sentir mais atraído pela necessidade emocional. Em relação ao mix de marketing de serviços, $96 \%$ concordaram mais com o elemento Praça, e 97\% em relação à retenção, concordaram mais com Pessoas. Lovelock (2006), afirma que clientes leais tendem a indicar a marca para outras pessoas e a ter a marca como sua primeira opção de compra frente a outros concorrentes.

Por tanto, o quinto objetivo da pesquisa foi respondido, a retenção de clientes influencia na lealdade, ficando então a necessidade por parte das empresas hoteleiras de se atentarem e investirem nas estratégias do mix de marketing de serviços.

\section{Considerações finais}

O presente trabalho teve como objetivo geral identificar se os elementos do mix de marketing de serviços adotado pelas empresas hoteleiras podem impactam na retenção dos clientes e em uma futura lealdade.

O primeiro objetivo específico consistiu em identificar o perfil dos respondentes. Notou-se que a maioria dos respondentes é do gênero feminino, na faixa etária entre 18 a 50 anos, e a maior parte residentes no Brasil, se hospedam motivo a lazer.

Em relação ao segundo objetivo específico, conclui-se que, para $91 \%$ dos respondentes preferem hotéis que proporcione momentos agradáveis. Portanto, a necessidade emocional é um dos principais fatores que levam o consumidor a contratar uma hospedagem.

Quanto ao terceiro objetivo específico de identificar a percepção do consumidor em relação ao mix de marketing de serviços, a pesquisa demonstrou que praça, preço, processos, pessoas, produto, promoção e evidências físicas influenciam nos processos de decisão do cliente.

No que se refere ao quarto objetivo específico de identificar se o mix de marketing de serviços influencia na retenção dos clientes, pode-se afirmar que os respondentes se sentem influenciados pelos elementos do mix, e dentre os que possuem maior grau de relevância, respectivamente estão: pessoas, praça e preço. Apesar de serem relevantes, promoções, produto, processos e evidências físicas foram menos perceptíveis.

Em relação ao último objetivo específico de identificar se a retenção leva a lealdade obteve-se uma tendência a concordância parcial. A pesquisa mostrou que os elementos do mix influenciam na retenção, e que através da mesma, os clientes estão propensos a se tornar leais.

Em relação ao objetivo geral, identificar se os elementos do mix de marketing de serviços adotados pelas empresas hoteleiras impactam na retenção dos clientes e em uma futura lealdade, conclui-se que os elementos têm influência na retenção e lealdade dos clientes. 
Sugere-se para estudos futuros a aplicação do questionário em outros setores, além disso, bem como uma análise dos fatores que levam a lealdade.

\section{Referências}

BLACKWELL, R. D.; MINIARD, P. W.; ENGEL, J. F. Comportamento do consumidor. 9. ed. São Paulo: Cengage Learning, 2009.

CASTELLI, G. Administração hoteleira. 7. ed. Caxias do Sul: Educs, 2000.

CHURCHILL, G. A. J.; PETER, P. Marketing: criando valor para os clientes. 2. ed. São Paulo: Saraiva, 2008.

ETZEL, M. J.; WALKER, B. J.; STANTON, W. J. Marketing. 11 a . São Paulo: Makron Books, 2001.

GRÖNROOS, C. Marketing: gerenciamento e serviços. 3. ed. Rio de Janeiro: Elsevier, 2009.

GUIMARÃES, N. Estudo do impacto do novo sistema de gestão hotelaria PHC, nas messes militares da guarnição de Lisboa com alojamento. [2013]. Disponível em: http://hdl.handle.net/10400.26/7634. Acesso em: 13 mai. 2019.

HOLANDA, M. I. A.; NASCIMENTO, G. S. Um estudo das novas tecnologias a serviço da hotelaria de Fortaleza-CE. Revista Ciências Administrativas, v.18, n.2, p.797-814, 2012. Disponível em: https://periodicos.unifor.br/rca/article/view/3347/pdf. Acesso em: 13 mai. 2019.

HOYER, D. Wayne; MACINNIS, Deborah J. Comportamento do Consumidor. 5. ed. São Paulo: Cengage Learning, 2011.

KOTLER, P. Administração de marketing. 10. ed. São Paulo: Prentice Hall, 2000.

KOTLER, P. Marketing 3.0: As forças que estão definindo o novo marketing centrado no ser humano. Rio de Janeiro: Elsevier, 2010.

KOTLER, P.. Marketing de A a Z: 80 conceitos que todo profissional precisa saber. 12. ed. Rio de Janeiro: Elsevier, 2003.

KOTLER, P.; ARMSTRONG, G. Princípios de marketing. 12. ed. São Paulo: Prentice Hall, 2009.

KOTLER, P.; ARMSTRONG, G. Princípios de marketing. 15. ed. São Paulo: Pearson Education do Brasil, 2014. 
KOTLER, P.; HAYES, T; BLOOM, P. Marketing de serviços profissionais: Estratégias inovadoras para impulsionar sua atividade, sua imagem e seus lucros. $2^{\mathrm{a}}$ ed. Manole, 2002.

KOTLER, P.; KELLER, K. L. Administração de marketing. 14. ed. São Paulo: Pearson Education do Brasil, 2012.

LOPES, E. L., TEIXEIRA, J. M., \& do AMARAL MORETTI, S. L. Valor de compra hedônico ou utilitário e sua influência no varejo: resultados de um survey no setor de construção civil. Organizações \& Sociedade, 19, 2012.

LOPES, H.; PEREIRA, C. \& VIEIRA, A. Comparação entre os modelos norte- americano (ACSI) e europeu (ECSI) de satisfação do cliente: um estudo no setor de serviços. Revista de Mackenzie, 2009, 10 (1):161-186.

LOVELOCK, C. Marketing de serviços: pessoas, tecnologia e resultados. 5. ed. São Paulo: Pearson / Prentice Hall, 2006.

LOVELOCK, C.; WIIRTZ J.; HEMZO, M. A.; Marketing de serviços: pessoas, tecnologia e estratégia. 7. ed. São Paulo: Pearson, 2011.

MAESTRI FILHO, W. J.; ALMEIDA, D. A. Proposta de plano para retenção de clientes da academia Planeta Fitness. Revista de Divulgação Científica Mafra, v. 17, n. 2, p.140$159,2010$.

MARTINS, A. Cresce a participação do Turismo no PIB nacional. [2019]. Disponível em: http://www.turismo.gov.br/\%C3\%BAltimas-not\%C3\%ADcias/12461-cresce-a-participa\%C3 \%A7\%C3\%A3o-do-turismo-no-pib-nacional.html>. Acesso em: 10 fev. 2019.

MASO, L. Marketing de relacionamento: O que é? Para que serve? Qual sua importância para o cliente? Revista de Administração e Ciências Contábeis do IDEAU. v. 5, n. 10.

Disponível em: <http://www.ideau.com.br/getulio/restrito/upload/revistasartigos/83_1.pdf>. Acesso em: 15 fev. 2019.

MILAN, G. S. A retenção de clientes como prática do marketing de relacionamento. In: G. S. MILAN; N. V. L. BRANCHI (org.), Administração mercadológica: teoria e pesquisas. Caxias do Sul, EDUCS, vol. 1, p. 177-195. 2004.

OLIVER, R. L. (1999). Whence consumer loyalty? Journal of Marketing, 63:33-44.

POPP, E. V.; SILVA, V. C.; MARQUES, J. A.; CARDONE, R.; FERNANDES, R. Caminhos do Futuro Ministério do turismo - AVT/IAP - NT/USP - Hotelaria e Hospitalidade. [2007]. Disponível em: http://www.turismo.gov.br/sites/default/turismo/o_ ministerio/publicacoes/downloads_publicacoes/Hotelaria_e_Hospitalidade.pdf. Acesso em: 20 fev. 2019. 
ROSSETTO, E. Estudo da qualidade hospitalar do hospital universitário regional dos Campos Gerais por meio do conceito da hospitalidade e humanização. [2014]. Disponível em: https://www2.unicentro.br/detur/files/2014/09/ESTUDO-DA-QUALIDADE-DOSERVI\%C3\%87O-HOSPITALAR-DO-HOSPITAL-UNIVERSIT\%C3\%81RIO-REGIONA L-DOS-CAMPOS-GERAIS-POR-MEIO-DO-CONCEITO-DA-HOSPITALIDADE-EHUMANIZA\%C3\%87\%C3\%83O.pdf?x64401. Acesso em: 13 mai. 2019.

SHETH, J. N.; MITTAL, B.; NEWMAN, B. I. Comportamento do cliente: indo além do comportamento do consumidor. São Paulo: Atlas, 2001.

SWARBROOKE, J.; HORNER, S. O comportamento do consumidor no turismo. São Paulo: Aleph, 2002.

ZEITHALM, A. V.; BITNER, J. M.; GREMLER, D. D. Marketing de serviços: a empresa com foco no cliente. 6 . Ed. Porto Alegre: AMGH Editora Ltda, 2014. 